\title{
Investigating the Role of Neighborhood- Based Management in Citizens' Participation in the Administration of Cities
}

\section{(Case Study: Al-Ghadir Neighborhood of Bojnourd)}

\author{
Mohammad Motamedi ${ }^{1}$ Azadeh Avazpour ${ }^{2}$ \\ 1. Lecturer of Islamic Azad University, Shirvan Branch, Northern Khorasan, Iran
}

2. Master Student of Geography and Urban Planning, Islamic Azad University, Shirvan Branch, Northern

Khorasan, Iran

E-mail: azadeh.avazpour@gmail.com

\begin{abstract}
The purpose of the present research is to investigate the role of neighborhood-based management in citizens' participation in the administration of cities (Bojnourd; Al-Ghadir Neighborhood). The research method is descriptive of survey type. The statistical population of this study is all citizens of Al-Ghadir neighborhood that are about 1,500 people. the Cochran sampling formula is used to ensure that the sample size is sufficient, and the simple random method was used that the number of people is 106 . For confidence, 310 questionnaires were distributed and 304 questionnaires were returned. Data collection tool was a researcher-made questionnaire that was judged by several professors and experts in the university, and finally, the agreed questionnaire was used as the data collection tool. For the reliability of the questionnaire, Cronbach's alpha was used, that the results indicated the reliability of the questionnaire. According to the obtained results, there is a significant relationship between neighborhood-based management and citizens' participation in the administration of Al-Ghadir neighborhood and also there is a significant relationship between trust, awareness, participation and correlation, and coherence with citizens' participation in the administration of Al-Ghadir neighborhood.
\end{abstract}

Keywords: Management, Neighborhood-Based, Citizens, Al-Ghadir Neighborhood of Bojnourd

Introduction

The irregular growth of urbanization in the modern era, especially the population increase in the cities of the country such as Bojnourd, has left many problems and issues that solving them are beyond the traditional management capability and requires the participation of all citizens in the administration of urban affairs and both, that are urban management and citizens become stronger and also weakened together. Since the nineteenth century in civil societies and the issue of membership in the government-nations has simultaneously become one of the important social and political topics, citizenship as a social and political process has been proposed as a serious interaction between the government and the nation (Ameli, 2001: 46).

Urban neighborhoods have long been considered as physical and social areas in Iranian cities and have been regarded as functional and geographical components of the cities that have had a basic role in the social life of the cities. Urban neighborhoods have been formed over time and have opened their place in the city. The city consisted of these coherent neighborhoods. Each one of the neighborhoods had all primary facilities and equipment needed by its residents, including bazaar, water reservoir, mosque, bath, and so on. The communication networks of the neighborhood were also hierarchical, linking various neighborhood spaces with each other. Neighborhoods affairs were administered through a self-assistance system, without requiring extensive and long-term management structures and due to the strong sense of correlation and trust among residents, all neighborhood affairs were resolved. In the traditional neighborhood system, a variety of social and cultural structures were spontaneously formed, guiding various neighborhood issues such as religious activities, establishing security, education, water distribution, construction of public places and facilities such as bath, water reservoir and so on. 
But the structure of urban neighborhoods has changed since the early twentieth century and has changed dramatically, especially in the last few decades. In the mentioned era, in addition to many changes that have taken place in the economic, social, and political relations in the world, and subsequently in Iran, the rapid expansion of urbanization along with the prevalence of modernism has also had a major impact on changing and transforming the structure and function of urban neighborhoods. The traditional neighborhood system collapsed without being replaced completely by the new system. With the establishment of state urban management institutions, top-down and centralized management replaced the neighborhood management system. In this system, the inhabitants of the neighborhoods did not have that much interference with the administration of the neighborhood affairs, and this issue quickly created a sense of the lack of identity and irresponsibility. Incomplete application of the new urban management principles and regulations on the one hand and assigning the responsibility of neighborhood affairs to non-local people on the other hanf, caused many problems in the neighborhoods. In recent years, in the search for mechanisms and methods of solving neighborhood problems, numerous topics such as neighborhood development, local partnership, neighborhood-based sustainable development, and the like have been raised in the sciences literature related to the city.

The administration of metropolises has nowadays become an important issue for urban managers. However, urban participation and management, and to a smaller scale, neighborhood management in our country is not a new phenomenon. Today, with the growth of urbanization and consequently the change of participation patterns, the necessity to review this concept and provide models appropriate to the modern needs of citizens is also quite tangible. Calling people to participate in the affairs of the city and neighborhood of residence is one of the theories of participatory management, and it can be said that it is one of the most important concepts of "Social Participation" of citizens that has nowadays been manifested in the form of neighborhood house and town and village councils. Human is the main center of development, and in fact, people's participation in urbanization, strengthens the foundations of urbanization legitimacy more.

Citizens' participation in urban affairs enhances citizens' understanding and awareness of the issues related to them and also the mutual need for each other, it helps creating a better society, and strengthens a community's abilities to coordinate people's actions in order to develop and improve valuable collective goods, and creates better governance and increases the opportunities to compile intelligent policies (Sarokhani and Amir Panahi, 2006: 133).

On the other hand, it provides this possibility for the citizens to strengthen their characteristics such as selfconfidence, sense of power, knowledge, and the ability to solve problems within themselves. By expanding their relationships with organizations and companies in planning, they contribute to organizational development and by discussing their common interests, community and solving conflicts help social development, thereby it makes the growth and progress of society in a general state (Bam, 2004: 1843).

Hence, this study addresses the way of people's participation in the society affairs as an important pillar of political, social and civic life development, and investigates individual-society relationships, to the way of internalizing participatory values and norms, to the way of using social participation potential and their trust in improving and enhancing social capital, the relationship between participation and trust and social belonging and the function and role of citizens' participation in the development and transformation of community and the like. In the local management area of Bojnourd, local institutions such as neighborhood houses, some popular organizations have conducted plans and programs aiming to make citizens participate and attracting citizens' trust, but they have not been continuous and the results obtained from them have not been exploited for effective planning.

For this purpose, the aim of investigating the ratio of willingness and participation of citizens in the administration of city and neighborhood affairs in the Al-Ghadir neighborhood of Bojnourd with a population of over 8,000 people and carrying out various cultural, social and welfare activities, is to find appropriate solutions in the administration of Bojnourd affairs with the neighborhood-based approach that by exploiting 40 to 50 questionnaires consisting of 20 questions is performed.

In fact, the neighborhood as a physical and social place that has the capability of doing people's collective and organizing actions can provide the proper conditions to increase people's participation and use their collective power and attracting their trust. The authors consider investigating this issue worth examining to see what are the shortcomings of the issue of neighborhood-based that has now been investigated in Bojnourd after metropolises and one of its reasons is the lowness of city council members for the city's growing population? Actually, what are the barriers to neighborhood-based development? To calculate the sample size, this issue will be investigated with the urban planning approach and citizens' participation in neighborhood management by the Cochran method and SPSS software.

Neighborhood-based management (focused on neighborhood house and assisting council) is introduced as the dependent variable of this research and citizens' partnership is introduced as the independent variable, which 
ultimately resolves the problems of urban affairs and city administration from down to top (neighborhood management to urban management).

In this regard, the research history related to the issue is mentioned that the research results of Panahi et al. (2011) of Tehran municipality have been a special endeavor to facilitate citizens' participation in the administration of urban affairs, and the results of Zahedi Yeganeh and Ghorbani (2011) can be mentioned regarding the tendency of neighborhood people to participate in group activities and decision-makings at their neighborhood level, as well as to distribute services inappropriate to the demands of the habitants of neighborhoods, and to create a system of neighborhood participation and regarding neighborhood as the basis in planning and so on. The results of study done by Hosseinzadeh and Dehcheshmeh (2012) showed that citizens' satisfaction $(r=0.37)$, motivational policies $(\mathrm{r}=0.26)$, social trust $(\mathrm{r}=0.41)$, and the type of municipality activity $(\mathrm{r}=0.47)$ had a significant relationship with people's participation and among the underlying variables there was only a correlation between the age and satisfaction of citizens. According to the findings of this research, the general status of citizens' participation is at moderate to the low limit, which is mainly due to the low level of the objective dimension of citizens' participation in urban life. In the investigation of Yazdanpanah (2003) it was specified that family factors, learning, creating relationships with others, and family members' participation in social activities have had a significant role in the ratio of social participation of the individuals under investigation, and McFarland and Thomas conducted a research that shows youth volunteer organizations affect their participation in the future. In their view, participation is usually specified by internal variables, that is, it is reproduced within the families. It depends very much on the social class and is usually sustained until adulthood, in particular participating in the youth volunteer organizations which includes activities such as social services, representation, speaking in public discussions, creates group identity more, and encourages later participation and the investigation of Shaditalab (2002) who was seeking to recognize the types of social participation of women and its related factors in Tehran who totally specified six types of participation: civic, supportive, cultural-recreational, local, religious, charity and participation in revolutionary activities, among which civic participation had the lowest mean and religious and charity participation were higher than other types of participation, and in general, the ratio of social participation of women in Tehran was at low level, and in the investigation of Bastani and Salehi Hikui (2007) it was shown that among the structural features of the network, network size is important. People with a larger network also have more trust in their network members, but network size can result in trust increase only by exchanging support with members. Contact size also has a relationship with interpersonal trust through supportive mechanisms, but intimacy in bonding has been the most important factor in mutual trust. Age, marital status, and gender indirectly have been effective on the ratio of trust through support and intimacy. The results of the study done byNauruan and Mozaffaripour (2013) showed that there is a positive and significant correlation between social capital and neighborhood-based management. Acquiring the highest score in the dimension of cognitive social capital by the awareness indicator indicates the efforts made at the neighborhood level by neighborhoodbased management in respect of informing. And the results of Alizadeh et al. (2013) specified that the role of people in the administration of city affairs (District 10 of Mashhad Municipality) was located respectively at the first to fifth ranks of priority in mental-spiritual participation (42\%), political participation (34\%), physical participation (27\%), financial participation (23\%), and instrumental participation (3\%). The ratio of overall participation resulting from the combination of participation ratio in the above five roles was also evaluated as relatively low with 26\% participation, and Pakdelnejad et al. (2012) also showed that the neighborhood management plan has established more interaction at the individual levels than at the institutional and organizational levels. It could not have the necessary effectiveness for the interaction between the executive, advisory and supervisory mechanisms either. In this article, the overall structures of neighborhood management in the form of an inspector, board of trustees and neighborhood management and the description of duties related to them have also been investigated.

\section{Research Hypotheses}

\section{The Major Hypothesis}

There seems to be a positive and significant relationship between neighborhood-based management and citizens' participation in the administration of Al-Ghadir neighborhood of Bojnourd.

\section{Minor Hypotheses}

- There seems to be a positive and significant relationship between citizens' trust and participation in the administration of Al-Ghadir neighborhood of Bojnourd.

- There seems to be a positive and significant relationship between citizens' awareness and participation in the administration of Al-Ghadir neighborhood of Bojnourd.

- There seems to be a positive and significant relationship between participation and correlation and citizens' participation in the administration of Al-Ghadir neighborhood of Bojnourd. 
- There seems to be a positive and significant relationship between citizen's coherence and participation in the administration of Al-Ghadir neighborhood of Bojnourd.

\section{- Research Method and the Area of Case Study}

The research method in this descriptive study is analytical of correlation type and it is cross-sectional in respect of time, and it is applied in terms of purpose, and the data collection tool is a researcher-made questionnaire consisting of the variables of awareness (5 questions), trust (4 questions), participation (6 questions), coherence and correlation (4 questions), and citizens' participation (20 questions). The statistical population of this study is all the citizens of Al-Ghadir of Bojnourd, about 1,500 people. The sample is part of the population. In the conventional sense, the part of the whole that has the characteristics of that whole is called sample. To ensure that the sample size is adequate, Cochran sampling formula and simple random method are used, that by using the Cochran formula it is 306 people that for assurance 310 questionnaires were distributed, and 304 questionnaires were returned. Al-Ghadir neighborhood has been located on the south side of Bojnourd and has 38 apartment units that all of them are residential units.

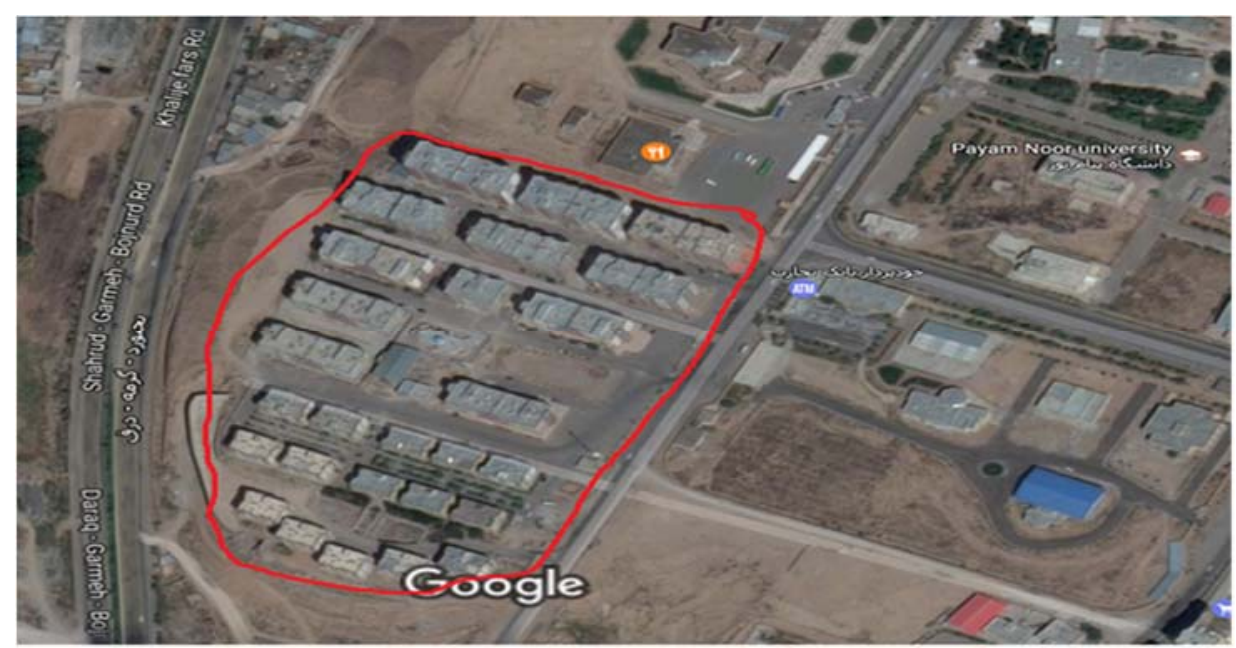

Map 1: Case Study Area

The reliability of the questionnaire was calculated using the Cronbach's alpha measurement method as shown in the following table.

Table 1: Reliability Statistics

\begin{tabular}{|c|c|c|}
\hline Variable & Questions & $\begin{array}{c}\text { Cronbach's } \\
\text { Alpha }\end{array}$ \\
\hline Trust & 4 & 0.702 \\
\hline Awareness & 5 & 0.824 \\
\hline Participation and Correlation & 6 & 0.713 \\
\hline Coherence and Correlation & 4 & 0.777 \\
\hline Citizens' Participation & 20 & 0.883 \\
\hline
\end{tabular}

SPSS 22 software was used for data analysis in two parts: descriptive statistics and inferential statistics. In the descriptive statistics, section mean, standard deviation, mode, percentage, frequency, dispersion indicators tests are used, and in the inferential statistics section Kolmogorov-Smirnov test and Pearson correlation, and linear regression are used to analyze and investigate the data.

\section{Findings}

According to data analysis, $234(77.0 \%)$ of the respondents are male and the remaining $70(23 \%)$ people are female, 79 people $(26 \%)$ are between the age of 25 and lower, 76 people $(25 \%)$ are between the age range of 25 to 26 years, 59 people $(19.4 \%)$ are between the age range of 36 to 45 years, and 90 people $(29.6 \%)$ are located in the age range of 46 years and higher, 135 people (44.4\%) have associate degree and lower, 68 people $(22.4 \%)$ of respondents have bachelor education, $67(22 \%)$ have master education, and 34 people $(11.2 \%)$ have doctoral education. 


\section{Hypotheses Test}

There seems to be a positive and significant relationship between neighborhood-based management and citizens' participation in the administration of Al-Ghadir neighborhood of Bojnourd.

Table 2: Hypothesis Test

\begin{tabular}{|c|c|c|c|c|c|}
\hline $\begin{array}{c}\text { Corrected } \\
\text { Explanation } \\
\text { Coefficient }\end{array}$ & F Statistics & B & $\begin{array}{c}\text { Std. } \\
\text { Error }\end{array}$ & $\mathrm{t}$ & $\begin{array}{c}\text { Significance } \\
\text { Degree }\end{array}$ \\
\hline 0.107 & 37.337 & 0.375 & 0.61 & 6.110 & 0.000 \\
\hline
\end{tabular}

The correlation coefficient is equal to 0.332 . The determination coefficient value is obtained 0.110 and this value indicates that 0.110 percent of neighborhood-based management changes are related to citizens' participation. The adjusted determination coefficient in this test is equal to 0.107. By upgrading one neighborhood-based management unit, 0.375 units of citizens' participation will be upgraded.

There seems to be a positive and significant relationship between citizens' trust and participation in the administration of Al-Ghadir neighborhood of Bojnourd.

Table 3: Hypothesis Test

\begin{tabular}{|c|c|c|c|c|c|}
\hline $\begin{array}{c}\text { Corrected } \\
\text { Explanation } \\
\text { Coefficient }\end{array}$ & F Statistics & $\mathrm{B}$ & $\begin{array}{c}\text { Std. } \\
\text { Error }\end{array}$ & $\mathrm{t}$ & $\begin{array}{c}\text { Significance } \\
\text { Degree }\end{array}$ \\
\hline 0.137 & 12.481 & 0.775 & 0.219 & 3.533 & 0.000 \\
\hline
\end{tabular}

The correlation coefficient is equal to 0.199 . The determination coefficient value is obtained 0.140 and this value indicates that 0.140 percent of the changes of trust are related to citizens' participation, and the adjusted determination coefficient of this test is equal to 0.137 . In other words, by upgrading one trust unit, 0.775 units of citizens' participation will be upgraded.

There seems to be a positive and significant relationship between citizens' awareness and participation in the administration of Al-Ghadir neighborhood of Bojnourd.

Table 4: Hypothesis Test

\begin{tabular}{|c|c|c|c|c|c|}
\hline $\begin{array}{c}\text { Corrected } \\
\text { Explanation } \\
\text { Coefficient }\end{array}$ & F Statistics & B & $\begin{array}{c}\text { Std. } \\
\text { Error }\end{array}$ & $\mathrm{t}$ & $\begin{array}{c}\text { Significance } \\
\text { Degree }\end{array}$ \\
\hline 0.124 & 8.500 & 0.549 & 0.188 & 2.915 & 0.004 \\
\hline
\end{tabular}

The correlation coefficient is equal to 0.166 . The determination coefficient value is obtained 0.127 and this value indicates that 0.127 percent of the changes of awareness are related to citizens' participation, and the adjusted determination coefficient is equal to 0.124 . By upgrading one awareness unit, 0.549 unit of citizens' participation will be upgraded.

There seems to be a positive and significant relationship between correlation and participation and citizens' participation in the administration of Al-Ghadir neighborhood of Bojnourd.

Table 5: Hypothesis Test

\begin{tabular}{|c|c|c|c|c|c|}
\hline $\begin{array}{c}\text { Corrected } \\
\text { Explanation } \\
\text { Coefficient }\end{array}$ & F Statistics & B & $\begin{array}{c}\text { Std. } \\
\text { Error }\end{array}$ & $\mathrm{t}$ & $\begin{array}{c}\text { Significance } \\
\text { Degree }\end{array}$ \\
\hline 0.197 & 33.460 & 1.035 & 0.179 & 5.784 & 0.000 \\
\hline
\end{tabular}


The correlation coefficient is equal to 0.316 . The determination coefficient value is obtained 0.100 and this value indicates that 0.100 percent of changes of participation and correlation are related to citizens' participation, and the adjusted determination coefficient in this test is equal to 0.197 . By upgrading one participation and correlation unit, 1.035 unit of citizens' participation will be upgraded.

\section{There seems to be a positive and significant relationship between citizens' coherence and participation in the administration of Al-Ghadir neighborhood of Bojnourd.}

Table 6: Hypothesis Test

\begin{tabular}{|c|c|c|c|c|c|}
\hline $\begin{array}{c}\text { Corrected } \\
\text { Explanation } \\
\text { Coefficient }\end{array}$ & F Statistics & B & $\begin{array}{c}\text { Std. } \\
\text { Error }\end{array}$ & $\mathrm{t}$ & $\begin{array}{c}\text { Significance } \\
\text { Degree }\end{array}$ \\
\hline 0.129 & 45.709 & 1.365 & 0.202 & 6.761 & 0.000 \\
\hline
\end{tabular}

The correlation coefficient is equal to 0.363 . The determination coefficient value is obtained 0.131 , and this value indicates that 0.131 percent of the changes of coherence are related to citizens' participation, and the adjusted determination coefficient in this test is equal to 0.129 . By upgrading one coherence unit, 1365 units of citizens' participation will be upgraded.

\section{- Discussing the Results}

Studying the later views of urban management illustrates the importance of an approach that considers and emphasizes citizens' participation in the form of urban neighborhoods. It is also possible to identify an inclusive tendency across various levels of government that seeks to exploit financial and human resources based on methods that delegate the administration of the process of development to neighborhoods and it can be referred to as neighborhood-basis.

From the perspective of urban sociology neighborhood, it is a social unit that is defined in terms of its social characteristics and its features. Social sciences scholars have defined the neighborhood in the form of a small residential area with the residents of this area and the interrelationships between them. Urban and social geographers in addition to social characteristics based on interrelationships, sense of neighborhood and coneighborhood, emphasize the concept of place and possessing territory in their interpretation of the neighborhood. In the urban planning perspective, the neighborhood is regarded as a dynamic socio-economic identity, composed of usages meeting the routine needs of the city. Therefore, in addition to physical dimensions, the neighborhood has a social nature, a definite area, a sense of correlation and mutual relationship between residents, collective identity, understanding shared destiny and access to required services and facilities.

According to the obtained results, there is a positive and significant relationship between neighborhood-based management and citizens' participation in the administration of Al-Ghadir neighborhood of Bojnourd,.Zahedi Yeganeh and Ghorbani (2011) found that citizens did not have that much participation in the administration of city affairs in Iran because of the reasons existed in the past, and today with little change compared to the past we witness few examples of citizens' participation in the administration of cities affairs, and the results of Khadem Al-Husseini et al. can be mentioned as the tendency of neighborhood people to participate in group activities and their neighborhood level decision-makings as well as distribution of services inappropriate with the demands of neighborhood residents, creating a neighborhood participation system and regarding the neighborhood as the basis in planning and so on. The results of Yazdanpanah (2003) showed that family factors, learning, creating a relationship with others and family members' participation in social activities have had a significant role in the ratio of social participation of the people under investigation. Nauruan and Mozafari Pour (2013) show that there is a positive and significant relationship between social capital and neighborhood-based management. Acquiring the highest score in the dimension of cognitive social capital by the awareness indicator indicates the efforts made at the neighborhood level by neighborhood-based management in terms of informing. According to the results, there is a positive and significant relationship between citizens' trust and participation in the administration of AlGhadir neighborhood of Bojnourd. Kermani et al. (2015) showed that the trust component could attract the attention of a part of the community as clients to the houses and the attitude of citizens and their trust in the neighborhood management plan was positive based on the evaluation and there is a positive and significant relationship between citizens' awareness and participation in the administration of Al-Ghadir neighborhood of Bojnourd, that Kermani et al. (2015) showed that informing component could attract the attention of a part of the community as clients to the houses, and the attitude of citizens and their trust in the neighborhood management plan was positive based on the evaluation, and Nauruan and Mozafari Pour (2013) show that the indicator of 
awareness illustrates some efforts made at the neighborhood level by neighborhood-based management in order to inform, and according to the results there is a positive and significant relationship between participation and correlation and citizens' participation in the administration of Al-Ghadir neighborhood of Bojnourd, that according to the results of Hosseinzadeh and Dehcheshmeh (2012) the overall status of citizens' participation had been at moderate to low level, and this point is largely due to the low level of the objective dimension of citizens' participation in urban life, and McFarland and Thomas participating in youth volunteer organizations which include activities such as social services, representation, speaking in public discussions, creates group identity more, and encourages later participation, and Kermani et al. (2015) showed that the component of participation could attract the attention of a part of the community as clients to the houses and the attitude of citizens and their trust in the neighborhood management plan is evaluated positive

Alizadeh et al. (2013) showed that participation was underestimated. Belly (2008) showed that participation will have a significant impact on the promotion of democratic local governments. Docherty et al. (2001) concluded that civic culture, political institutions, public policies, and education are effective in citizens' participation.

According to the results, there is a positive and significant relationship between citizens' coherence and participation in the administration of Al-Ghadir neighborhood of Bojnourd, and Kermani et al. (2015) showed that participation component could attract the attention of a part of the community as clients to the houses and the attitude of citizens and their trust in the neighborhood management plan was positive based on the evaluation.

\section{- Suggestions Obtained from the Research}

Holding neighborhood gatherings with the presence of urban management and to inform about the neighborhoodbased approach and creating an opportunity for decision-making about the method of its implementation by the inhabitants themselves;

Utilizing neighborhood capitals in the form of public gathering spaces and places, especially religious and respectful places, paying attention to the presence of neighborhood elders and trustees, holding customary rituals and gatherings, and the presence of public groups and institutions; these are useful and effective to begin and advance the neighborhood-based realization process. Recognizing and applying these capitals, especially at the start of the process and in the absence of compiled managerial infrastructures can be very effective and helpful.

One of the factors in the development and progress of a community is the comprehensive participation and cooperation of people. Therefore, neighborhood-based management authorities by attracting people's support and creating trust and confidence regarding the foreseen programs can bring people's participation and cooperation and to realize this point they should pay more attention to the performance of public institutions in order not to deviate from their route and be able to put their words to the people into action in order to attract people's trust towards themselves and to enhance their sense of satisfaction and pleasure.

In order to create trust among the people in neighborhood-based management, it is suggested that factors such as the system of suggestions, survey, need assessment, consultation are created and inform all people in this respect.

Diversification in communication and information methods and the use of face-to-face and in-person methods;

It is suggested to make maximum use of the capacity of cyberspaces and introducing them to the citizens and to provide new methods of local informing and the feedback of the results of neighborhood management activities and programs as cross-sectional and periodically to the citizens.

The process of neighborhood-based realization is shaped by the interaction between urban management and neighborhood residents or their cooperation with each other. The role of the local community in welcoming this approach and its continuation should also be taken into account. Having adopted the underlying policies and creating neighborhood-based grounding institutions by urban management, the role of the local community in the form of participation and responsibility in the neighborhood-based process will be a determinant role, and if this role is not played by the residents, the process of realizing neighborhood-based will automatically be stopped. This issue recalls the need to recognize and estimate neighborhood social capital accurately and to empower neighborhoods lacking it.

Teaching participation methods and the ways of using urban management communication and informing system to citizens in the form of workshops, publications, and gatherings focusing on a neighborhood scale.

Specialized activities in the neighborhoods should not be limited to the development and creation of centers by neighborhood managers, and other centers and nongovernmental organizations active in the neighborhood or area should be attractable and cooperate with these houses. 


\section{References}

[1] Bastani, Susan and Salehi Hikui, Maryam (2007), "Social Capital, Network and Gender and Investigating the Structural, Interactive, and Functional Characteristics of Men's and Women's Social Networks in Tehran", Social Sciences Letter, No. 30, pp. 63 - 95

[2] Panahi, Mohammad Adel et al. (2011), "Organizing Citizens' Participation in the Administration of City Affairs by Neighborhood-Based Approach", Report of Tehran Center for Studies and Planning

[3] Hosseinzadeh, Ali Hossein, Fadaiedeh, Hamid, Cheshmeh (2012), "Investigating Social Factors Affecting Citizens' Participation in Urban Affairs (Case Study: Shahrekord)" Urban Sociological Studies, Vol. 2, No. 5, Winter, pp. 59-82, 2012

[4] Sarokhani, Bagher and Amir Panahi, Mohammad (2006), "Building Power in Family and Social Participation" Women's Research Quarterly Journal, Vol. 4, No. 3, pp. 31-60

[5] Shaditalab, Jaleh (2002), "Public Participation in Tehran Management" Jahad Monthly Journal, Tehran, 2002, No. 162

[6] Alizadeh, Dr. Katayoun, Razavinejad, Morteza, Radfar, Mina (2013), "Investigating the Role and Participation of People in the Administration of Urban Affairs (Case Study: District 10 of Mashhad Municipality)" Quarterly Journal of Urban Planning Studies, Vol. 1, No. 1, Spring, pp. 61- 87

[7] Kermani, Ali Nouri, Rezaie, Ali Akbar, Pakdelnejad, Mostafa (2015), "Evaluating Participatory Planning of Neighborhood Management Plan in Tehran", Urban Sociological Studies, Vol. 5, No. 15, pp. 183-218

[8] Nauruan, Farshad, Mozafari Pour, Najmeh (2013), "Evaluating Neighborhood-Based Management Performance with Emphasis on Social Capital Indicators; Case Study: Seven Neighborhoods, District 1, Region 21, Tehran Municipality", Journal of Fine Arts, Architecture \& Urban Planning, Vol. 18, No. 4, Winter, pp. 47-56

[9] Yazdan Panah, Leila (2003), "Investigating the Factors Affecting the Social Participation of Citizens Aged 18 Years and over in 22 Districts of Tehran", Ph.D. Thesis, Allameh Tabataba'i University

[10] Baum, H.S (2004), "Citizen Participation" International Encyclopedia of the Social Behavioral Sciences, pp.1840-1846 